\title{
DESENVOLVIMENTO SUSTENTÁVEL COMO VANTAGEM COMPETITIVA NA GERAÇÃO DE VALOR PARA AS ORGANIZAÇÕES EMPRESARIAIS
}

\author{
SUSTAINABLE DEVELOPMENT AS A COMPETITIVE ADVANTAGE IN \\ GENERATING VALUE FOR BUSINESS ORGANIZATIONS
}

\author{
Willian di Gaetano Bassi - willian.bassi@fatec.sp.gov.br \\ Angelita Moutin Segoria Gasparotto - angelita.gasparotto@fatec.sp.gov.br \\ Gilmerson Inácio Gonçalves - gilmerson@yahoo.com.br \\ Faculdade de Tecnologia de Matão (Fatec) - Matão - São Paulo - Brasil
}

DOI: 10.31510/infa.v17i1.705

\begin{abstract}
RESUMO
Este artigo objetiva analisar os processos industriais de uma empresa que atua na produção de suco de laranja, como suas operações se relacionam com os conceitos de sustentabilidade, valor compartilhado e sua sintonia com os objetivos de desenvolvimento sustentável (ODS). O estudo aborda também temas relevantes para produção sustentável bem como apresenta os motivadores para a mudança de comportamento do mercado consumidor, baseando-se nos conceitos de fronteiras planetárias e limites de crescimento. O objetivo do estudo é entender como os conceitos de sustentabilidade podem contribuir para a agregação de valor à empresa e como suas operações se relacionam com estes conceitos, sua sintonia com os objetivos de desenvolvimento sustentável (ODS), impactos e os resultados gerados advindos do desenvolvimento sustentável da organização. Os resultados obtidos demostram que as organizações empresariais que são sustentavelmente responsáveis pode obter vantagens competitivas haja visto a mudança no comportamento dos clientes e investidores. Concluiu-se que a empresa estudada possui em seu planejamento estratégico e em seu âmago a inclusão de ações sustentáveis em todas as operações de sua cadeia de valor e esta forma de fazer negócios vem trazendo resultados positivos a organização e para a sociedade onde ela está inserida.
\end{abstract}

Palavras-chave: Sustentabilidade. Impacto Econômico. Valor Compartilhado. Competição Empresarial

\begin{abstract}
This article aims to analyze the industrial processes of a company that operates in the production of orange juice, as well as its operations relate to the concepts of sustainability, shared value and its harmony with development objectives (ODS). The study also addresses relevant topics for sustainable production besides presenting the motivators for changing consumer market behavior, based on the concepts of planetary boundaries and growth limits. the aggregation of value to the company and how its operations relate to these concepts, its harmony with the objectives of sustainable development (SDGs), impacts and the results generated from the sustainable development of the organization. The results show that business organizations that are sustainably responsible may gain competitive advantages considering the change in the behavior of customers and investors. It was concluded that the company studied has in its
\end{abstract}


strategic planning and at its core the inclusion of sustainable actions in all operations of its value chain and this way of doing business has brought positive results to the organization and to the society where it is inserted.

Keywords: Sustainability. Economic Impact. Shared Value. Business Competition

\section{INTRODUÇÃO}

\subsection{Contexto e Objetivo}

Cada vez mais o mercado consumidor, governos (países) e as organizações empresariais, estão dando mais atenção à temática de sustentabilidade. Em 2015, a Organização das Nações Unidas lançou os objetivos de desenvolvimento sustentável (ODS), que determinou o curso global para a realização de ações que visam acabar com a pobreza, promover a prosperidade e o bem-estar de todos, proteger o meio ambiente bem como enfrentar as mudanças climáticas. Os conceitos de Fronteiras Planetária e dos Limites do Crescimento para entender a importância de trabalhar de forma sustentável e o porquê desta mudança de comportamento por parte da população, empresas, governos e são abordados nos estudos de Meadows et al. (1972).

Por sua vez, as organizações socialmente responsáveis vêm apresentando posturas condizentes com esta nova realidade, elas buscam mais que respeitar leis, pagar impostos, oferecer segurança e saúde a seus colaboradores além de atuar para a preservação do meio ambiente e entregar um produto de qualidade a seus clientes. Assim os impactos negativos tendem a ser neutralizados e os positivos ampliados e impulsionados. Através do conceito de valor compartilhado de Michel Porter (2011), o autor aborda como como as organizações geram vantagens competitivas bem como valores tangíveis e intangíveis através da solução de problemas, gerando lucro neste processo.

O objetivo do estudo é entender como os conceitos de sustentabilidade podem contribuir para a agregação de valor à empresa e como suas operações se relacionam com estes conceitos, sua sintonia com os objetivos de desenvolvimento sustentável (ODS), impactos e os resultados gerados advindos do desenvolvimento sustentável da organização.

\section{FUNDAMENTAÇÃO TEÓRICA}

\subsection{As Fronteiras Planetária e os Limites do Crescimento (Limits to Growth)}

De acordo com Rockstrom et al. (2009), no contexto da comunidade científica, mais precisamente no campo das ciências naturais, cada vez torna-se mais consensual a ideia de que a crescente ação da humanidade em relação às modificações no meio ambiente, pressionam o 
sistema terrestre podendo levar a uma mudança súbita ou irreversíveis em larga escala do ambiente global. Segundo Viola e Franchini (2012), com base nesta situação foram identificadas fronteiras planetárias (Planetary Boundaries) que delimitam até onde a sociedade (humanidade) poderia operar de maneira segura, continuando a se desenvolver e prosperar pelas próximas gerações, atravessar estas fronteiras, acarretariam entrar em uma zona de risco de rompimento ambiental sistêmico.

O conhecimento destes limites oferece uma maneira de discutir a sustentabilidade não de maneira isolada, mas sim de forma mais ampla e sistêmica. As fronteiras identificadas são nove, sendo elas: mudanças climáticas; acidificação dos oceanos; ozônio; ciclo biogeoquímico do nitrogênio e fósforo; uso da água doce e o ciclo hidrológico global; mudanças no uso da terra; biodiversidade; poluição química, concentração de aerossóis, sendo que destas fronteiras, as : mudanças climáticas, redução da biodiversidade e ciclo de nitrogênio já foram extrapoladas peala humanidade.

Segundo o "Stockholm Resilience Centre", no período de 2013-2016 o Conselho Empresarial Mundial Sobre o Desenvolvimento Sustentável, realizou um fórum para 200 empresas, incluindo grandes marcas conhecidas mundialmente e fazendo uso da estrutura de limites planetários, moldou suas estratégias para a Ação 2020, que consiste em uma plataforma com ações das empresas para aliar a agenda do setor privado com a da sociedade e propor soluções de negócios e políticas públicas. Este modelo, das fronteiras planetária gerou grande interesse dentro da ciência e política (Planetary boundaries research, 2013-2016).

Em consonância com o modelo anteriormente apresentado, o estudo de Meadows et al. (1972). intitulado “Limits to Growth”, concluem que o declínio ambiental, combinado à aceleração do crescimento populacional e da escassez de recursos, teria a capacidade, sem uma correção do seu rumo, de precipitar o colapso da civilização em 2100. Estes conceitos evidenciam que os recursos naturais são finitos e para que a sociedade e empresas possam continuar a prosperar, essa limitação deve ser levada em consideração na estratégia dos negócios, visando ações sustentáveis em suas operações.

\subsection{Sustentabilidade na Estratégia de Negócio das Empresas}

Os objetivos de desenvolvimento social (ODS), estão intrinsecamente ligados a modelos de gestão empresarial que visam promover a sustentabilidade em suas operações, neste sentido há a necessidade de conhecer estes objetivos bem como as definições de sustentabilidade, para auxiliar no entendimento de como esta temática impacta na gestão empresarial bem como nos processos produtivos e demais atividades da organização. 
Os objetivos de desenvolvimento sustentável da Organização das Nações Unidas (ONU), são: erradicação da pobreza; fome zero e agricultura sustentável; saúde e bem-estar; educação de qualidade; igualdade de gênero; água limpa e saneamento; energia limpa e acessível; trabalho decente e crescimento econômico; indústria, inovação e infraestrutura; redução das desigualdades; cidades e comunidades sustentáveis; consumo e produção responsáveis; ação contra a mudança global do clima; vida na água; vida terrestre; paz, justiça e instituições eficazes finalizando com parcerias e meios de implementação. Os objetivos são interligados, o sucesso de um ODS está relacionado com o cumprimento de temas relacionados a outros objetivos. De acordo com o administrador do Programa das Nações Unidas para o Desenvolvimento, Achim Steiner (2015), os ODS trabalham com o espírito de parceria para se fazer as escolhas certas visando a melhoria da qualidade de vida, de forma sustentável, para a atual e futuras gerações. Em diversas formas, reflete o objetivo do Programa das Nações Unidas para o Desenvolvimento - PNUD”. Com os ODS, o mundo dos negócios ganhou uma nova "estrela polar" para um mundo em constante mudança (The United Nations Global CompactAccenture Strategy CEO Study, 2016, p. 6)

A definição de sustentabilidade mais propagada é o da Comissão Brundtland (WCED, 1987), considerando que o desenvolvimento sustentável deve satisfazer às necessidades da geração presente sem comprometer as necessidades das gerações futuras. Essa definição deixa evidente um dos princípios básicos de sustentabilidade, a visão de longo prazo, uma vez que os interesses das futuras gerações devem ser considerados. De acordo com Almeida (2002), o valor econômico, contém a economia formal e informal, o ambiental ou ecológico leva as empresas a considerarem o impacto de suas atividades sobre o meio ambiente, na forma de utilização dos recursos naturais e contribui para a integração da administração ambiental nas operações da organização e finalmente o valor social, conecta o aspecto social as qualidades humanas, por exemplo as habilidades, dedicação e experiencia abarcando o ambiente interno e externo.

Segundo Manfrin et al. (2013), modelos de sustentabilidade estão sendo criados tendo como referência o "Triple Bottom Line" (People, Planet, Profit). Várias empresas estão comprometidas com este modelo e criam atividades de desenvolvimento sustentável, caracterizadas pela produção através de processos não poluentes, que conservam energia e os recursos naturais bem como desenvolvidos e entregues de forma segura e saudável aos colaboradores, consumidores e sociedade de forma criativa e socialmente gratificante a todos.

Para Hart e Milstein (2004), uma empresa sustentável é aquela que contribui com o desenvolvimento sustentável, gerando, simultaneamente, benefícios econômicos, sociais e 
ambientais - conhecidos como os três pilares da sustentabilidade. "O conceito sustentabilidade, que se apoia nos aspectos ambiental, social e econômico financeiro, deve ser visto como uma oportunidade de negócio a ser levada ao centro da estratégia das companhias" (PORTER, 2007, p. 86). Não se pode deixar de evidenciar que a relação entre estas três dimensões não se dão de forma igualitária, nesta relação a dimensão econômica é a mais frágil.

Com base neste conceito Porter e Kramer lançaram em 2011 a criação de valor compartilhado difundindo a ideia que a sociedade está caminhando para um novo modelo de capitalismo, e este é o capitalismo do valor compartilhado. O raciocínio que rege a criação de valor compartilhado é o que a competitividade de uma empresa e o bem-estar da sociedade onde ela está inserida são dependentes, desta forma reconhecer e capitalizar sobre esta relação entre o desenvolvimento (progresso) social e o econômico pode estimular a próxima onda do crescimento global e redefinir o capitalismo (PORTER; KRAMER, 2011).

Ainda segundo Porter e Kramer (2011), nos últimos tempos, os negócios estão sendo vistos como a causa dos problemas sociais, ambientais e econômicos. Enxergam as organizações como se elas prosperassem à custa da sociedade. No entanto, surge uma nova maneira da interação social ser capaz de lidar com esta situação. Neste sentido, as empresas que entreguem produtos, serviços e tecnologias que se adaptem as necessidades atuais, podem criar vantagem competitiva sustentável. Drucker (1993) e Porter e Kramer (2011), entendem que a as empresas não possuem uma única responsabilidade que é o desempenho econômico, para os segundos autores, as empresas têm o dever perante suas comunidades que não é limitado apenas ao lucro, elas devem buscar uma abordagem aos problemas da sociedade que coincidam com seu "core business" que é principal negócio da empresa, desta forma podendo transforma-los em oportunidades comerciais.

Para Hart e Prahalad (2002), as populações mais humildes (economicamente) levantam um grandioso e novo desafio para as empresas, este seria o de vender para os mais pobres e concomitantemente auxilia-los na melhoria de suas vidas por intermédio da produção e distribuição de serviços e produtos que são sensíveis a sua cultura, sustentável ambientalmente e economicamente lucrativos, isto é um modo de competir.

Segundo Hart e Milstein (2004), os desafios globais associados à sustentabilidade, vistos a partir da ótica dos negócios, podem ajudar a identificar estratégias e práticas que contribuam para um mundo mais sustentável e a, simultaneamente, direcionar o valor ao acionista. Lucchesi (2012) define que as empresas responsáveis e preocupadas com a sustentabilidade conquistam resultados melhores e geram valores aos que estão próximos a ela. Pelo fato da responsabilidade 
social e sustentabilidade não ser apenas uma opção politicamente correta atualmente passou a ser um ponto de visão estratégica. Empresas que não se adequar a este novo comportamento está destinada a perder competitividade em médio prazo.

A pesquisa realizada por Kiron et al. (2013), deixa evidente a fundamental importância de haver o compromisso da alta gerência (gestores) das empresas bem como o estabelecimento de indicadores relacionados a sustentabilidade e a comunicação clara sobre a responsabilidade da empresa no que concerne a sustentabilidade, uma das dificuldades neste ponto é a dificuldade em mensurar os efeitos intangíveis das ações sustentáveis e como motivador que levaria a mudança na forma de operação da organização seria a preferência do consumidor por produtos sustentáveis, escassez de recursos, concorrentes mais preocupados com a temática, pressões políticas e legais. Segundo Sucena e Marinho (2019), a evidenciação ambiental é um conjunto de meios que a empresa adota para comunicar de maneira completa seus escopos ambientais às partes interessadas. O Relatório de Sustentabilidade de uma organização é a principal plataforma para reportar a relação da empresa com o meio ambiente no qual ela está inserida.

Desta forma uma análise crítica que pode ser feita até aqui pelo autor, é que as empresas desenvolvidas sustentavelmente, podem alcançar melhores resultados como por exemplo ampliar e manter os consumidores desta forma gerando lucro para empresa, além dos valores intangíveis advindos destas ações sustentáveis como por exemplo o fortalecimento da marca, outra análise que pode ser feita, é que as organizações não lucram causando problemas sociais, esta é uma visão muito periférica, quanto mais a pesquisa avança, mais claro fica que as empresas obtém retornos com a solução dos problemas sociais, econômicos e ambientais, por exemplo há várias ações como diminuição da emissão de poluentes, possuir um ambiente de trabalho seguro e tornar a empresa mais eficiente nas suas operações, torna a empresa mais competitiva, haja visto que estas ações são sinais de bons processos.

\section{PROCEDIMENTOS METODOLÓGICOS}

\subsection{Metodologia}

A metodologia de pesquisa adotada para o desenvolvimento deste artigo abrange o levantamento bibliográfico (livros, artigos e matérias), de estudo de caso realizado através da análise dos relatórios de sustentabilidade de uma empresa que atua no setor de agronegócio na fabricação de suco de laranja e duas visitas técnicas a mesma empresa.

O conceito de metodologia é assim definido por Freitas e Prodanov (2013, p. 14) “a metodologia é a aplicação de procedimentos e técnicas que devem ser observados para 
construção do conhecimento, com o propósito de comprovar sua validade e utilidade nos diversos âmbitos da sociedade". A pesquisa bibliográfica, que é assim definida por Rampazzo (2005, p. 53) "procura um problema a partir de referências teóricas publicadas. Pode ser realizada independentemente, ou como parte de outros tipos de pesquisa". Segundo Yin (2010, p. 39), “o estudo de caso é uma investigação empírica que investiga um fenômeno contemporâneo em profundidade e em seu contexto de vida real, especialmente quando os limites entre o fenômeno e o contexto não são claramente evidentes".

Ilustração 01: Protocolo de Estudo de Caso

\begin{tabular}{|c|c|}
\hline \multicolumn{2}{|r|}{ PROTOCOLO DE ESTUDO DE CASO } \\
\hline $\begin{array}{l}\text { Questões de } \\
\text { Pesquisa }\end{array}$ & $\begin{array}{l}\text { Como a sustentabilidade na estratégia dos negócios de uma organização } \\
\text { empresarial em sintonia com os objetivos de desenvolvimento sustentável } \\
\text { da Organização das Nações Unidas, influenciam na geração de resultados e } \\
\text { os impactos para a empresa, ambiente e sociedade? }\end{array}$ \\
\hline $\begin{array}{l}\text { Unidade de } \\
\text { Análise }\end{array}$ & $\begin{array}{l}\text { Estudo de caso em uma empresa que trabalha na cadeia produtiva dos } \\
\text { produtos da laranja. }\end{array}$ \\
\hline $\begin{array}{l}\text { Limite de } \\
\text { Tempo }\end{array}$ & Agosto de 2019 a dezembro de 2019. \\
\hline Local & Região de Matão / SP \\
\hline $\begin{array}{l}\text { Validade da } \\
\text { Pesquisa }\end{array}$ & $\begin{array}{l}\text { Análise dos dados obtidos com base em visita técnica, referencial } \\
\text { bibliográfico e nos relatórios de sustentabilidade da empresa estudada. }\end{array}$ \\
\hline $\begin{array}{l}\text { Validade } \\
\text { interna }\end{array}$ & $\begin{array}{l}\text { Adequação às diretrizes contidas na literatura sobre sustentabilidade; } \\
\text { Objetivos de Desenvolvimento Sustentável (ODS) da Organização das } \\
\text { Nações Unidas; Valor Compartilhado. }\end{array}$ \\
\hline Confiabilidade & Protocolo de estudo de casos. \\
\hline
\end{tabular}

Fonte: Autores (2019)

\subsection{Estudo de Caso}

Para a realização do estudo de caso o foram realizadas duas visitas a empresa, sendo a primeira em sua planta industrial com o objetivo de conhecer os processos industriais, e a segunda focada em uma conversa com o Gerente de Sustentabilidade da organização, além das visitas, fora feito uma profunda análise dos quatro relatórios de sustentabilidade disponibilizados pela empresa, referentes as safras dos anos 2014-2015, 2015-2016, 2016-2017 e 2017-2018.

A primeira visita realizada em 10 de outubro de 2019, foi acompanhada pelo engenheiro de processos da empresa, onde ficou claro que a empresa adota em suas operações métodos sustentáveis tais como a geração de energia a partir de fontes renováveis, tratamento de seus resíduos, bem como o tratamento da água utilizada e seu reuso, além do cuidado com a cadeia de valor de seus produtos principais, para que esta, seja sustentavelmente responsável visando obter seus produtos através de processos que proporcione saúde, qualidade de vida e bem-estar 
as pessoas.

A segunda visita, realiza em 18 de novembro de 2019, acompanhada pelo responsável do gerenciamento de sustentabilidade da organização. Nesta segunda vista pode-se apurar através de anotações que a empresa possui em seu âmago a estratégia de fazer negócios de forma sustentável, uma vez que este está incorporado em todas suas operações desde a produção agrícola passando pelos processos industriais e na logística de distribuição do produto acabado, neste segundo encontro para nortear e otimizar a reunião haviam perguntas pré formuladas, todavia, durante a conversa outros assuntos correlatos entraram em pauta.

\subsection{Análise do Estudo de Caso}

Após as visitas e análise dos relatórios de sustentabilidade observou-se que as ações da empresa estão alinhadas com os ODS, também fora observado que a gestão socioambiental está distribuída através de cinco pilares a saber: Governança para o Desenvolvimento Sustentável; Mudanças Climáticas e Ambientais; Cadeia de Valor Responsável; Engajamento Social; Produtos para um Estilo de Vida Saudável. Esta visão ficou mais clara durante a análise dos relatórios de sustentabilidade (disponibilizados no site da empresa) pois estes demonstravam a qual ODS a ação apresentada se refere.

Fora observado que a empresa elabora seus relatórios de sustentabilidade em conformidade com a as diretrizes da “Global Reporting Initiative (GRI) ” que é uma organização internacional independente que foi criada para auxiliar empresas, governos e outras organizações, a entender e comunicar impactos relativos à sustentabilidade (por exemplo mudanças climáticas, direitos humanos, corrupção e outros), que por sua vez ajudam a identificar os impactos das operações da organização sobre os aspectos sociais, econômicos e ambientais, fazendo que as informações sejam confiáveis, relevantes e apresentadas de maneira padronizada, auxiliando assim na mensuração e verificação dos resultados das ações sustentáveis, observando se os esforços estão sendo válidos e em que é possível investir.

Durante o estudo de caso, observou-se que a empresa desenvolve ações voltadas a sustentabilidade de seus processos atendendo as necessidades atuais sem deixar de se preocupar com as necessidades futuras da sociedade, como exemplo destas ações há o controle dos riscos da produção e certificação da cadeia de valor, além de contribuir com o desenvolvimento socioambiental, estes elementos podem ser melhor assimilados observando alguns números da safra 2017-2018, com a produção recorde de suco NFC e mais de 23 mil pessoas impactadas pelas ações sociais da empresa.

Esta forma de operacionalizar seus negócios podem ser melhor definidas através das 
ações em três dimensões (ondas) sendo: a primeira onda o produto ofertado a seus clientes, produzido de forma a trazer benefícios a saúde e bem-estar dos consumidores, fazendo uso de matéria prima natural e redução do desperdício de alimentos, haja visto que se faz o uso de $100 \%$ da laranja. A segunda onda é referente aos impactos sociais, melhor exemplificado através de seus números, contando com colaboradores diretos ao redor de 12 mil pessoas , 857 pessoas envolvidas com atividades de voluntariado, inclusão de 343 profissionais com deficiência (PcDs), mais de 400 pessoas beneficiadas através da agricultura familiar, desenvolvimento profissional de jovens, da faixa etária de 16 a 19 anos , 170 mil horas de treinamento, e finalmente a terceira onda tem relação com os impactos ambientais, nesta dimensão podemos observar ações na direção do desenvolvimento ambiental, mais de 17 mil hectares de áreas de conservação (mata atlântica e cerrado) destinados à sustentação da biodiversidade, plantio de 31 mil mudas de espécies nativas, proteção dos animais, geração de 86 mil MWh de energia renovável, 57\% da energia usada é de origem renovável vindas da biomassa e hidroelétricas, produção de biomassa a partir das plantas cítricas erradicadas (equivale a $10 \%$ da demanda industrial), irrigação com economia de até $50 \%$ fazendo o uso de tecnologias de irrigação de baixo volume (gotejamento) ,captura de carbono nos pomares, transferência de tecnologia e incentivo ao controle biológico de pragas.

Outas ações que merecem destaque diz respeito a conversão da frota diesel para flex (diesel e GNV), a filiação à "SAI Platform" que objetiva criar um futuro em que as pessoas, o planeta e as soluções empresariais sustentáveis se unam para garantir um setor agrícola viável e resiliente. Em 2016, 100 fazendas da empresa estudada foram auditadas com base em padrões de agricultura sustentável e a sua evolução em inovação e aceleração do plano de transformação digital. Na questão de certificações a empresa passa por dez auditorias externas, que analisam toda sua cadeia produtiva e de valor segundo o último relatório de sustentabilidade, referente a safra 2017-2018, visando que todos os processos sejam sustentáveis.

\section{RESULTADOS}

Os resultados da pesquisa demonstram que a organização sob estudo, em seu planejamento estratégico e em sua forma de fazer negócios que interiorizaram os conteúdos sustentáveis propostos, desenvolvimento sustentável, associado ao engajamento de todos colaboradores e assim poder obter vantagens competitivas haja visto a mudança no comportamento dos clientes e investidores, uma vez que estes estão se importando cada vez mais com os problemas globais. Os estudos dos limites planetários e de crescimento, mostram 
que caso não haja mudanças na forma atual que o mundo atua a sociedade e a economia poderão entrar em colapso em poucos anos.

Outro fator a se destacar é a vantagem competitiva que as organizações podem obter através do valor compartilhado, haja visto que seus negócios geram lucro e esse por sua vez poder financiar ações sustentáveis, mudando a visão que muitos possuem em que as empresas são causadoras de problemas ambientais e sociais, quando na verdade elas podem ser parte da solução, pois possuem recursos (financeiros, humanos e materiais) que podem potencializar estas ações de maneira mais eficaz que os governos e ONG's. No que tange a projetos socioambientais, a empresa estudada desenvolve ações voltadas para educação, esportes e desenvolvimento da comunidade onde ela possui seus negócios, a pesquisa mostrou que a empresa é mantenedora de diversos projetos sociais nas áreas de educação, esporte, diversidade, proteção ambiental e apoio a atletas paralímpicos, estes são alguns exemplos do desenvolvimento e engajamento social da organização.

Como motivador a este interesse do mercado consumidor, estão fatores como a visão que os recursos planetários são finitos e necessitam de uso responsável, também há o surgimento de um novo modelo de capitalismo, o de geração de valor compartilhado, modelo este onde as empresas através de suas ações sustentáveis geram desenvolvimento econômico e social ao mesmo tempo que criam vantagens competitivas para si, desta forma trazendo retornos positivos ao seu negócio e para sociedade, este novo modelo pode estimular a próxima onda de crescimento mundial.

Este planejamento estratégico faz com que todas as operações de sua cadeia de valor sejam sustentáveis e isto traz resultados positivos à organização, bem como para a sociedade onde ela está inserida, conferindo a empresa vantagem competitiva no mercado global de suco de laranja, além de gerar valores tangíveis e intangíveis para a marca. Este retorno é parte de um ciclo onde as ações sustentáveis geram valores através da venda de seus produtos, que por sua vez alimenta as ações sociais, econômicas e ambientais da empresa, esta retroalimentação faz com que o negócio se desenvolva e cresça e isto é gerar valor de forma compartilhada, desta forma fazendo com que a empresa possa proporcionar a entrega de um produto de qualidade e socialmente responsável bem como o seu cliente ao adquiri-lo possa também contribuir para estas ações sustentáveis.

Deve-se registrar que todo o grupo empresarial e consequentemente a planta industrial visitada, possui engajamento total por parte de seus colaboradores em todos os níveis hierárquicos (estratégico, tático e operacional) com o desenvolvimento sustentável da 
organização e na busca de uma gestão transparente e ética visando o desenvolvimento econômico e melhoria da qualidade de vida de todos os envolvidos .Este envolvimento de todos os funcionários desde a alta administração até produção é um fator preponderante para o sucesso do desenvolvimento sustentável da empresa.

Como resultado deste engajamento, além do retorno econômico, pode ser observado pela empresa ter sido vencedora da edição de 2019 do Prêmio Talento em Sustentabilidade com dois projetos o de biomassa de laranjeira e o de primeiro veículo de carga 100\% a gás do Brasil, nas categorias meio ambiente e produtividade e eficiência respectivamente. O Prêmio reconhece as práticas dos empregados e estagiários que geram benefícios e tornam as empresas melhores para as pessoas e para o planeta.

\section{CONCLUSÕES}

Há sim relação entre a geração de vantagens competitivas e retorno econômico às empresas que são sustentavelmente responsáveis. No que tange aos objetivos de desenvolvimento sustentável a empresa analisada está em sintonia com estes objetivos preconizados pela ONU demostrando desta forma o compromisso com as gerações futuras sem deixar de atender as necessidades do presente.

Com relação a empresa estudada, os autores concluíram que esta possui de maneira intrínseca em sua forma de fazer negócio a preocupação com o desenvolvimento sustentável da organização e como suas operações podem estar alinhadas com este modelo de estratégia de negócios a fim de mitigar os impactos negativos criando e impulsionando ações que geram impactos positivos na sociedade, economia e ambiente. Esta atenção em relação a questão da sustentabilidade, faz com que o mercado opte por empresas socialmente responsáveis na hora de consumir produtos industrializados.

\section{REFERÊNCIAS}

ALMEIDA, F. O bom negócio da sustentabilidade. Rio de Janeiro: Nova Fronteira, 2002.

Conheça os novos 17 Objetivos de Desenvolvimento Sustentável da Organização das Nações Unidas. Disponível: https://nacoesunidas.org/conheca-os-novos-17-objetivos-dedesenvolvimento-sustentavel-da-onu/amp/. Acesso em 24 de outubro de 2019, 09:50h.

DRUCKER, P. Sociedade Pós-Capitalista. 5. ed. São Paulo: Pioneira, 1993 
FREITAS, P. Metodologia do Trabalho Científico: métodos e técnicas da pesquisa e do trabalho acadêmico. 2. ed. Novo Hamburgo: Universidade Feevale, 2013.

HART, S.; PRAHALAD, C. K. The fortune at the bottom of the pyramid. Strategy+Business Vol. 26, January, pages 54-67, 2002.

KIRON, D.; KRUSCHWITZ, N.; HAANAES, K.; REEVES, M.; GOH, E. (2013). The innovation bottom line. MIT Sloan Management Review, 54(3), 1-21. Disponível em https://sloanreview.mit.edu/projects/the-innovation-bottom-line/\#chapter-7. Acesso em $16 / 11 / 2019$ às $20: 31 \mathrm{~h}$.

LUCCHESI, S. Sustentabilidade e Responsabilidade Social nas Empresas Brasileiras. Disponível: https://administradores.com.br/noticias/sustentabilidade-e-responsabilidadesocial-nas-empresas-brasileiras. Acesso em 25 de outubro de 2019, 14:03h.

MANFRIN, P. M. et al. Um panorama da pesquisa em operações sustentáveis. Prod. Online.2013, vol.23, n.4, pp.762-776. Disponível em: $<$ http://www.scielo.br/scielo.php?script=sci_arttext\&pid=S0103$65132013000400008 \& \operatorname{lng}=$ pt\&nrm $=$ iso $>$.

MEADOWS, D. H.; RANDERS, J.; BEHRENS, W.W. Limits to Growth. New York, 1972. Momento de Ação Global Para as Pessoas e o Planeta. Disponível: https://nacoesunidas.org/pos2015/. Acesso em 23 de outubro de 2019, 14:30h.

PORTER, M. E. O Capitalismo do valor compartilhado. HSM Management. Setembro/outubro, 2011

PORTER, M. E.; KRAMER M. The Big Idea: Creating Shared Value. Harvard Business Review, Vol. 89, No. 12, January/February 2011.

The link between competitive advantage and corporate social responsibility. Harvard Business Review, Vol. 84 No. 12, pp. 78-92, 2006.

Programa das Nações Unidas para o Desenvolvimento, S. O que são os objetivos de desenvolvimento sustentável? Disponível: https://www.br.undp.org/content/brazil/pt/home/sustainable-development-goals.html. Acesso em 25 de outubro de 2019, 15:13h.

RAMPAZZO, L. Metodologia Científica: para alunos dos cursos de graduação e pósgraduação. 3. ed. São Paulo: Edições Loyola, 2002.

ROCKSTRÖM, J. et al. Planetary boundaries: exploring the safe operating space for humanity. Ecology and Society, v. 14, n. 2, p. 32, 2009. Disponível em: $<$ http://www.ecologyandsociety.org/vol14/iss2/art32/>. Acesso em: 12 fev. 2011.

Stockholm Resilience Centre, S. Planetary boundaries research. Disponível: https://www.stockholmresilience.org/research/planetary-boundaries.html. Acesso em 24 de outubro de 2019, 13:13h. 
STUART, L. H.; MARK B. M. Criando valor Sustentável. Texto traduzido por Pedro F. Bendassolli Artigo originalmente publicado na Academy os Management Executive, v. 17, n. 2, p. 56-69, maio 2003.

SUCENA, E.; MARINHO, M. M. O. Environmental disclosure analysis of sustainability reports the Brazilian and international brewing industry based on Global Reporting Initiative GRI. Gest. Prod., São Carlos, v. 26, n. 3.

VIOLA, E.; FRANCHINI, M.. Os limiares planetários, a Rio+20 e o papel do Brasil. Cad. EBAPE.BR, Rio de Janeiro, v. 10, n. 3, p. 470-491, set. 2012. Disponível em. http://dx.doi.org/10.1590/S1679-39512012000300002. Acessos em 25 nov. 2019.

YIN, R. K. Estudo de Caso: planejamento e métodos. 4.ed. Porto Alegre: Bookman, 2010. 